Article

\title{
Study of the Relationship between Sigma Receptor Expression Levels and Some Common Sigma Ligand Activity in Cancer Using Human Cancer Cell Lines of the NCI-60 Cell Line Panel
}

\author{
Evangelia Sereti ${ }^{1,2}$, Chrisiida Tsimplouli ${ }^{1}$, Elisavet Kalaitsidou ${ }^{1}$, Nikos Sakellaridis ${ }^{1}$ (D) \\ and Konstantinos Dimas ${ }^{1, *(D)}$ \\ 1 Department of Pharmacology, Faculty of Medicine, University of Thessaly, 41500 Larissa, Greece; \\ evangelia.sereti@med.lu.se (E.S.); xrisida@med.uth.gr (C.T.); e.kalaitsidou@students.uu.nl (E.K.); \\ nsakella@uth.gr (N.S.) \\ 2 Department of Translational Medicine, Division of Urological Cancers, Lund University, \\ SE 20502 Malmö, Sweden \\ * Correspondence: kdimas@med.uth.gr
}

Citation: Sereti, E.; Tsimplouli, C.; Kalaitsidou, E.; Sakellaridis, N.; Dimas, K. Study of the Relationship between Sigma Receptor Expression Levels and Some Common Sigma Ligand Activity in Cancer Using Human Cancer Cell Lines of the NCI-60 Cell Line Panel. Biomedicines 2021, 9, 38. https://doi.org/10.3390/ biomedicines 9010038

Received: 29 December 2020 Accepted: 30 December 2020 Published: 5 January 2021

Publisher's Note: MDPI stays neutral with regard to jurisdictional clai$\mathrm{ms}$ in published maps and institutional affiliations.

Copyright: () 2021 by the authors. Licensee MDPI, Basel, Switzerland. This article is an open access article distributed under the terms and conditions of the Creative Commons Attribution (CC BY) license (https:// creativecommons.org/licenses/by/ $4.0 /)$.

\begin{abstract}
Sigma $(\sigma)$ receptors have attracted great interest since they are implicated in various cellular functions and biological processes and diseases, including various types of cancer. The receptor family consists of two subtypes: sigma-1 $(\sigma 1)$ and sigma-2 $(\sigma 2)$. Both $\sigma$ receptor subtypes have been proposed as therapeutic targets for various types of cancers, and many studies have provided evidence that their selective ligands (agonists and antagonists) exhibit antiproliferative and cytotoxic activity. Still, the precise mechanism of action of both $\sigma$ receptors and their ligands remains unclear and needs to be elucidated. In this study, we aimed to simultaneously determine the expression levels of both $\sigma$ receptor subtypes in several human cancer cell lines. Additionally, we investigated the in vitro antiproliferative activity of some widely used $\sigma 1$ and $\sigma 2$ ligands against those cell lines to study the relationship between $\sigma$ receptor expression levels and $\sigma$ ligand activity. Finally, we ran the NCI60 COMPARE algorithm to further elucidate the cytotoxic mechanism of action of the selected $\sigma$ ligands studied herein.
\end{abstract}

Keywords: sigma receptors; sigma ligands; cancer; SIGMAR1; PGRMC1; TMEM97; NCI60 COMPARE analysis

\section{Introduction}

Sigma receptor is a class of receptors that have been the subject of intensive pharmacological research since their discovery in 1976 by Martin et al. [1]. Since then, considerable progress has been made, especially in the last years. It is now known that the family consists of two members: the sigma-1 $(\sigma 1)$ and sigma-2 $(\sigma 2)$ receptors, which are substantially different from each other. Sigma-1 has been cloned by two different groups independently $[2,3]$ and is now widely accepted as a membrane receptor and a chaperone protein with multiple cellular functions [4]. Until recently, the identification of sigma-2 receptor was a matter of debate. In 2011, it was proposed that the PGRMC1 may harbor binding sites for sigma ligands [5]. A few years later in 2017, Alon et al. published evidence showing that the sigma-2 receptor is in fact identical to TMEM97 [6], which is now the prevailing theory. Sigma-2/TMEM97, a member of the insulin-like growth factor binding proteins, is a protein that is reported to be increased in several types of cancer [7]. To complicate things even more, a 2018 study reported that $\sigma 2 /$ TMEM97 forms a trimeric complex with PGRMC1 and the low-density lipoprotein receptor (LDLR), which is responsible for the rapid internalization of the low-density lipoprotein (LDL) in HeLa cells, a human cervical cancer cell line [8]. That work suggested that both PGRMC1 and TMEM97 could in fact be part of a more complex receptor that can bind o2-ligands. 
Interestingly, both sigma subtypes have been proposed as therapeutic targets for several diseases and pathological conditions, with various types of cancer being amongst them [9]. However, the precise mechanism of their action is still a matter of debate, even though many independent studies have provided evidence of antiproliferative and cytotoxic activity for both the sigma-1 and sigma-2 receptor ligands [10].

In this study, we try to shed some light on the relationship of the $\sigma 1$ and $\sigma 2$ receptors and the anticancer activity of sigma ligands. To this aim, we used Western blot (WB) to study the expression levels of $\sigma 1$, PGRMC1, and $\sigma 2 /$ TMEM97 receptors in several human cancer cell lines, representing nine different cancer types. Most of the tested cell lines included in this study are also included in the NCI60 cell line panel list that is widely used for the in vitro testing of potential anticancer drugs [11]. In addition to the WB studies, we further addressed the in vitro antiproliferative activity of some commonly used $\sigma 1$ and $\sigma 2$ ligands against those cell lines to (a) test the efficacy of these ligands against various human cancer types, (b) compare their activity under the same experimental conditions, and (c) assess if there whether any correlation of their activity in relation to the expression of the receptors.

\section{Materials and Methods}

\subsection{Cell Culture}

All cell lines used were purchased from the National Cancer Institute (National Institutes of Health, Bethesda, MD, USA), and were cultured in RPMI 1640 (Roswell Park Memorial Institute 1640) medium (Cat. No. 31870025; Thermo Fisher Scientific, Waltham, MA, USA) supplemented with 5\% fetal bovine serum (Cat. No. 1001G; Biosera, Nuaille, France), 2 mM L-glutamine (Cat. No. XC-T1715; Biosera, Nuaille, France), and 100 U/mL penicillin and $100 \mu \mathrm{g} / \mathrm{mL}$ streptomycin (Cat. No. XC-A4122; Biosera, Nuaille, France). Cell cultures were maintained at $37{ }^{\circ} \mathrm{C}$ in a humidified incubator with a $5 \% \mathrm{CO}_{2}$ air atmosphere.

\subsection{Western Blot Analysis}

Cell lysis was performed in T-PER tissue protein extraction reagent (Cat. No. 78510; Thermo Fisher Scientific, Waltham, MA, USA) supplemented with 1\% protease and phosphatase inhibitor cocktail (Cat. No. 5872; Cell Signaling Technology, Beverly, MA, USA). Cell lysates were then sonicated ( 3 cycles, $10 \mathrm{~s} /$ cycle) and centrifuged at 13,000 rpm for $30 \mathrm{~min}$ at $4{ }^{\circ} \mathrm{C}$, and supernatants were then collected. Protein concentration was determined using a Pierce BCA Protein Assay Kit (Cat. No. 23227; Thermo Fisher Scientific, Waltham, MA, USA). Lysates containing equal amount of protein $(20 \mu \mathrm{g})$ were run on a $10 \%$ acrylamide gel and transferred to a $0.22 \mu \mathrm{m}$ pore size polyvinylidene difluoride (PVDF) membrane, Immobilon-PSQ Transfer Membrane (Cat. No. ISEQ85R; Merck, Millipore, Darmstadt, Germany). Membranes were blocked for $1 \mathrm{~h}$ at room temperature with the appropriate blocking buffer, according to each antibody's specific protocol, and then incubated overnight at $4{ }^{\circ} \mathrm{C}$ with rabbit anti-SIGMA1 antibody (Cat. No. 61994; Cell Signaling Technology, Beverly, MA, USA), rabbit anti-PGRMC1 antibody (Cat. No. 13856; Cell Signaling Technology, Beverly, MA, USA), or rabbit anti-TMEM97 antibody (Cat. No. NBP1-30436; Novus Biologicals, Centennial CO, USA). All antibodies were used at a 1:1000 dilution. Finally, membranes were incubated with the secondary horseradish peroxidase-conjugated anti-rabbit antibody (Cat. No. 7074; Cell Signaling Technology, Beverly, MA, USA) at 1/6000 dilution, developed with Clarity Western enhanced chemiluminescence (ECL) Substrate (Cat. No. 170-5060; Bio-Rad Laboratories, Hercules, CA, USA) and detected with Uvitec Cambridge chemiluminescence imaging system with the help of Alliance Software (ver. 16.06) (Uvitec Cambridge, Cambridge, UK).

\subsection{Cell Viability Assay}

The cytotoxic effect of the sigma ligands Siramesine (kindly offered by H. Lundbeck A/S), PB28 dihydrochloride (Cat. No. sc-204834; Santa Cruz Biotechnology, Dallas, TX, 
USA), rimcazole dihydrochloride (Cat. No. 1497; Tocris, Abingdon, United Kingdom), BD1047 dihydrobromide (Cat. No. 0956; Tocris, Abingdon, United Kingdom), and SM-21 maleate (Cat. No. sc-204289; Santa Cruz Biotechnology, Dallas, TX, USA) was determined using sulforhodamine B (SRB) colorimetric assay. Cell viability was determined at the beginning of each experiment by trypan blue dye exclusion method and was always greater than $97 \%$. Cells were seeded into a flat bottom 96-well plate at a density of 5000 cells per well, $24 \mathrm{~h}$ before treatment. Sigma ligands were dissolved in dimethyl sulfoxide (DMSO) and were serially diluted in culture medium to acquire the desired concentrations. The final concentration of DMSO in each cell culture was no higher than $0.1 \%$. After $48 \mathrm{~h}$ treatment, cells were fixed by gentle addition of 50\% (v/v) trichloroacetic acid (TCA) (Cat. No. A1431; Applichem, Darmstadt, Germany) to each well and stained for $1 \mathrm{~h}$ at $4{ }^{\circ} \mathrm{C}$. Cells were washed (three times) with slow running tap water; excess water was removed by gentle tapping onto a paper towel and the plates were allowed to air-dry at room temperature (RT). A solution of $0.04 \%(w / v)$ SRB (Cat. No. S9012; Sigma-Aldrich, St Louis, MO, USA) in $1 \%(v / v)$ acetic acid (Cat. No. 45731; Fluka, Buchs, Switzerland) was subsequently used to dye cells for $10 \mathrm{~min}$ at RT. After incubation, the excess dye was removed by repeated rinses with $1 \%(v / v)$ acetic acid (Cat. No. 45731; Fluka, Buchs, Switzerland) and cell monolayers were allowed to dry at RT. The protein-bound dye was dissolved in $10 \mathrm{mM}$ Tris base solution by incubation for $10 \mathrm{~min}$ at $37^{\circ} \mathrm{C}$ followed by solubilization in an orbital shaker for $10 \mathrm{~min}$. Absorbance was measured at $540 \mathrm{~nm}$ in a BioTek EL311 microplate reader (BioTek Instruments, Winooski, VT, USA). From the generated dose-response curves, we determined the $\mathrm{GI}_{50}$ ( $50 \%$ cell growth inhibition), TGI (total growth inhibition), and $\mathrm{LC}_{50}$ ( $50 \%$ lethal concentration) parameters. Growth inhibition of $50 \%\left(\mathrm{GI}_{50}\right)$ is calculated from $((\mathrm{Ti}-\mathrm{Tz}) /(\mathrm{C}-\mathrm{Tz})) \times 100=50$. The drug concentration resulting in total growth inhibition (TGI) is calculated from $\mathrm{Ti}=\mathrm{Tz}$. The $\mathrm{LC}_{50}$ indicating a net loss of cells following treatment is calculated from $((\mathrm{Ti}-\mathrm{Tz}) / \mathrm{Tz}) \times 100=-50$. In these formulas Tz represents a measurement of the cell population for each cell line at the time of drug addition, $\mathrm{Ti}$ is a measurement representing the growth of cells in the presence of a given concentration of the drug and $C$ the measurement of the control cells at the end of the $48 \mathrm{~h}$ incubation period.

Following standardization, the $\mathrm{GI}_{50} \mathrm{z}$-scores were defined and cell lines were categorized, with z-scores $\geq 0.8$ categorized as being resistant and z-scores $\leq 0.8$ as being sensitive to the compounds tested.

\subsection{Statistical Analysis}

All data are presented as the mean \pm SD of at least 3 independent experiments. A twotailed Student's $t$-test was used to calculate the statistical significance between sigma receptors' expression levels in the cancer cell lines tested versus cell lines with the lowest protein expression levels. A two-way ANOVA with either Bonferroni's or Tukey's post hoc test was used to determine statistical significance of sigma ligands' antiproliferative activity within cell lines of the same cancer type. Data normalization was performed by z-score analysis. Pearson's linear correlation coefficient ( $r$ ) was calculated to measure the strength of the linear relationship between the antiproliferative efficacy of the selected sigma ligands to the expression levels of sigma receptors. The NCI60 COMPARE algorithm was used to calculate the Pearson correlation coefficient (PCC) of the sigma ligands against compounds with known mechanism of action (MoA) in the National Cancer Institute (NCI) database. Differences were considered significant (rejection of the null hypothesis) when $p \leq 0.05$.

\section{Results}

\section{1. $\sigma 1$ Receptor, PGRMC1, and $\sigma 2 / T M E M 97$ Were Heterogeneously Expressed in 23 Human} Cancer Cell Lines

For the first time in the literature, the expression levels of $\sigma 1$ receptor, PGRMC1, and o2/TMEM97 were studied simultaneously by Western blot analysis in 23 human cancer cell lines. The cell lines used represent nine different types of cancer: lung, colon, CNS, melanoma, ovarian, breast, renal, prostate, and pancreatic ductal adenocarcinoma (PDAC). 
Figure 1a shows that $\sigma 1$, PGRMC1, and $\sigma 2 /$ TMEM97 receptors were expressed with different expression patterns in the studied cell lines. Sigma-1 receptor showed the highest expression levels in NCI-H460 (lung cancer) and HCT-15 (colon cancer) cell lines, while the lowest expression levels were reported in CAKI-1, SN12C (kidney cancer), OVCAR-3, OVCAR-5 (ovarian cancer), HCT-116 (colorectal cancer), and MCF7 (breast cancer) cell lines (Figure 1b). Sigma-2/TMEM97 receptor was found to be highly expressed in NCI-H460 (lung cancer), HCT-15 (colorectal cancer), and MCF7 (breast cancer) cell lines, with low expression levels in MDA-MB-435 (melanoma), SF268 (CNS cancer), and MDA-MB-231 (breast cancer) cell lines. Regarding PGRMC1 receptor, BxPC-3 (pancreatic cancer) and MCF-7 (breast cancer) cell lines expressed the highest levels, while the lowest levels were observed in NCI-H23 (lung cancer), HCT15, HCT116 (colon cancer), MDA-MB-231 (triple negative breast cancer), and T-47D (breast cancer) cell lines (Figure 1c). Despite the different profiles reported above, it seemed that there were few exceptions where the $\sigma$ receptors did share similarities in terms of their expression levels. Specifically, in NCI-H460 and HCT-15 cell lines, both $\sigma 1$ and $\sigma 2 /$ TMEM97 showed the highest expression levels among all the cell lines studied. Moreover, MCF7 cell line expressed high levels of both 62 /TMEM97 and PGRMC1 receptors. However, $\sigma 1$, PGRMC1, and $\sigma 2 /$ TMEM97 were generally expressed differentially, even between cell lines of the same cancer type. Examples of this were $\sigma 1$ expression in ovarian and breast cancer, PGRMC1 expression in lung and breast cancer, and $\sigma 2 /$ TMEM97 in melanoma and breast cancer cell lines.

\subsection{In Vitro Antiproliferative Efficacy of Sigma Ligands}

The in vitro antiproliferative efficacy of five common sigma ligands was investigated in the same panel of the 23 human established cancer cell lines in which we earlier investigated the expression levels of $\sigma 1$, PGRMC1, and $\sigma 2 /$ TMEM97 receptors. The selected sigma ligands were siramesine and PB28 dihydrochloride, referred to in the literature as $\sigma 2$ agonists with high $\sigma 2$ receptor affinities [12,13], and rimcazole [14], SM-21 maleate [15], and BD-1047 dihydrobromide [16], referred to as $\sigma 1 / \sigma 2$ antagonists. The chemical structures of the sigma ligands tested are shown in Figure 2.

Twenty-three established human cancer cell lines were treated with the sigma ligands for $48 \mathrm{~h}$ at various concentrations $(100,10,1$, and $0.1 \mu \mathrm{M})$, and a cell viability assay (SRB) was performed. Dose-response curves were generated after incubation with different concentrations of the various sigma ligands (Figure 3).

\section{a}

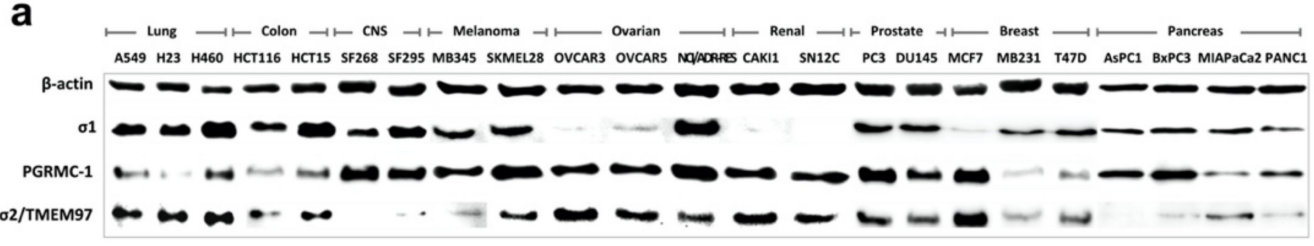

Figure 1. Cont. 
b

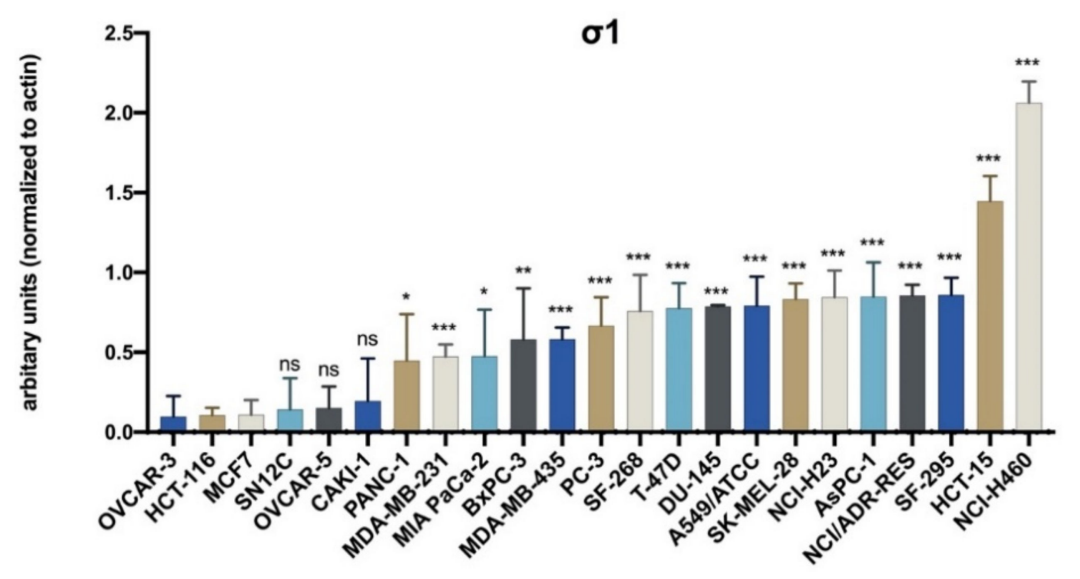

c

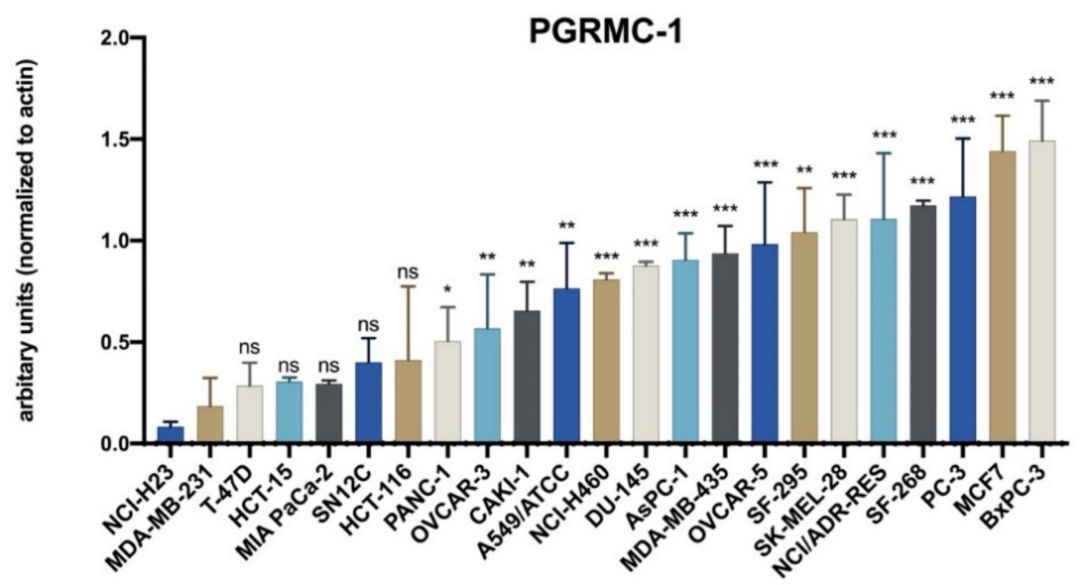

d

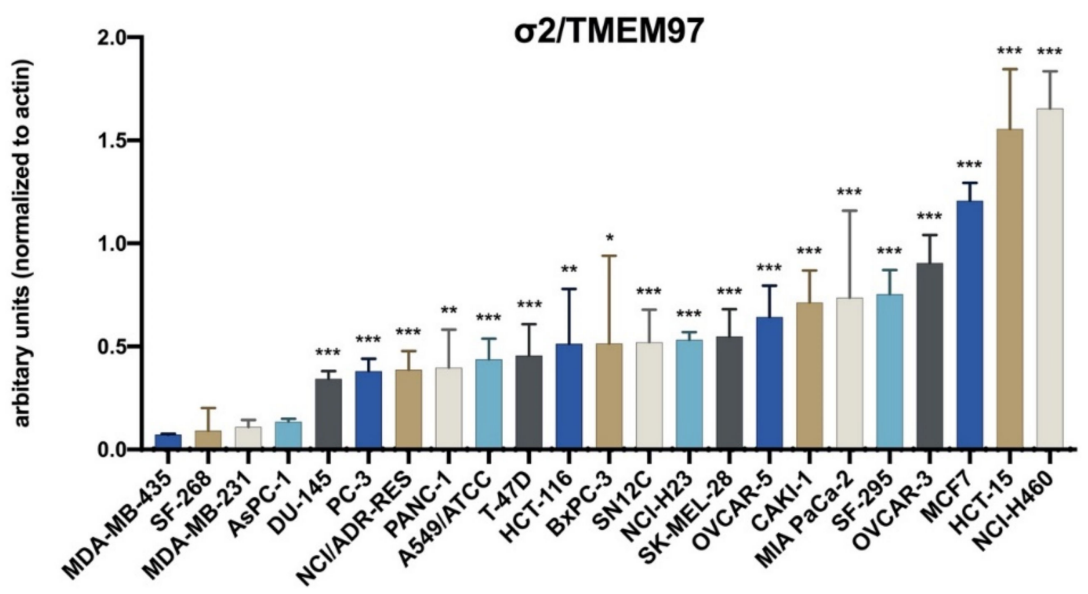

Figure 1. Expression levels of $\sigma 1$, PGRMC1, and $\sigma 2 /$ TMEM97 in the 23 human cancer cell lines. (a) Western blot analysis of $\sigma 1$, PGRMC1, and $\sigma 2 /$ TMEM97 expression in 23 human cancer cell lines representing nine different cancer types. $\beta$-Actin was used as a loading control. Bar graphs of $\sigma 1$ (b), PGRMC1 (c), and o2/TMEM97 (d) relative expression levels normalized to $\beta$-actin. Results are expressed as mean \pm SD of at least three independent experiments. Statistical significance was calculated versus cell lines with the lowest protein expression levels: OVCAR-3, HCT-116, MCF-7 (b); NCI-H23, MDA-MB-231 (c); and MDA-MB-435, SF-268, MDA-MB-231, AsPC-1 (d). ${ }^{*} p \leq 0.05$; ** $p \leq 0.01 ;{ }^{* * *} p \leq 0.001$; ns: not significant. 


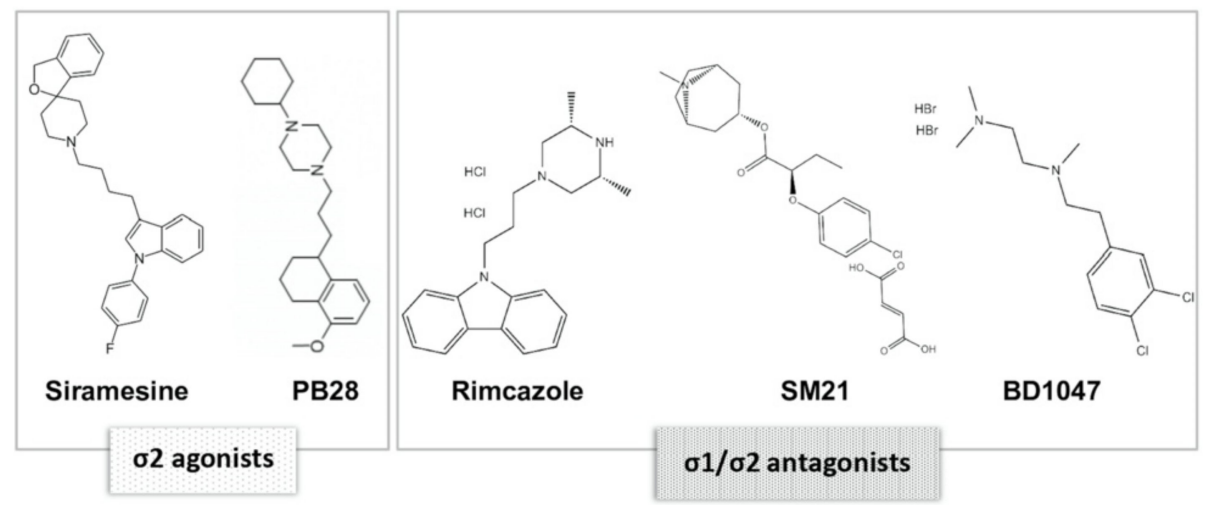

Figure 2. Chemical structures of the selected sigma receptors agonists and antagonists siramesine, PB28 dihydrochloride (PB28), rimcazole, SM21 maleate (SM21), and BD1047 dihydrobromide (BD1047).
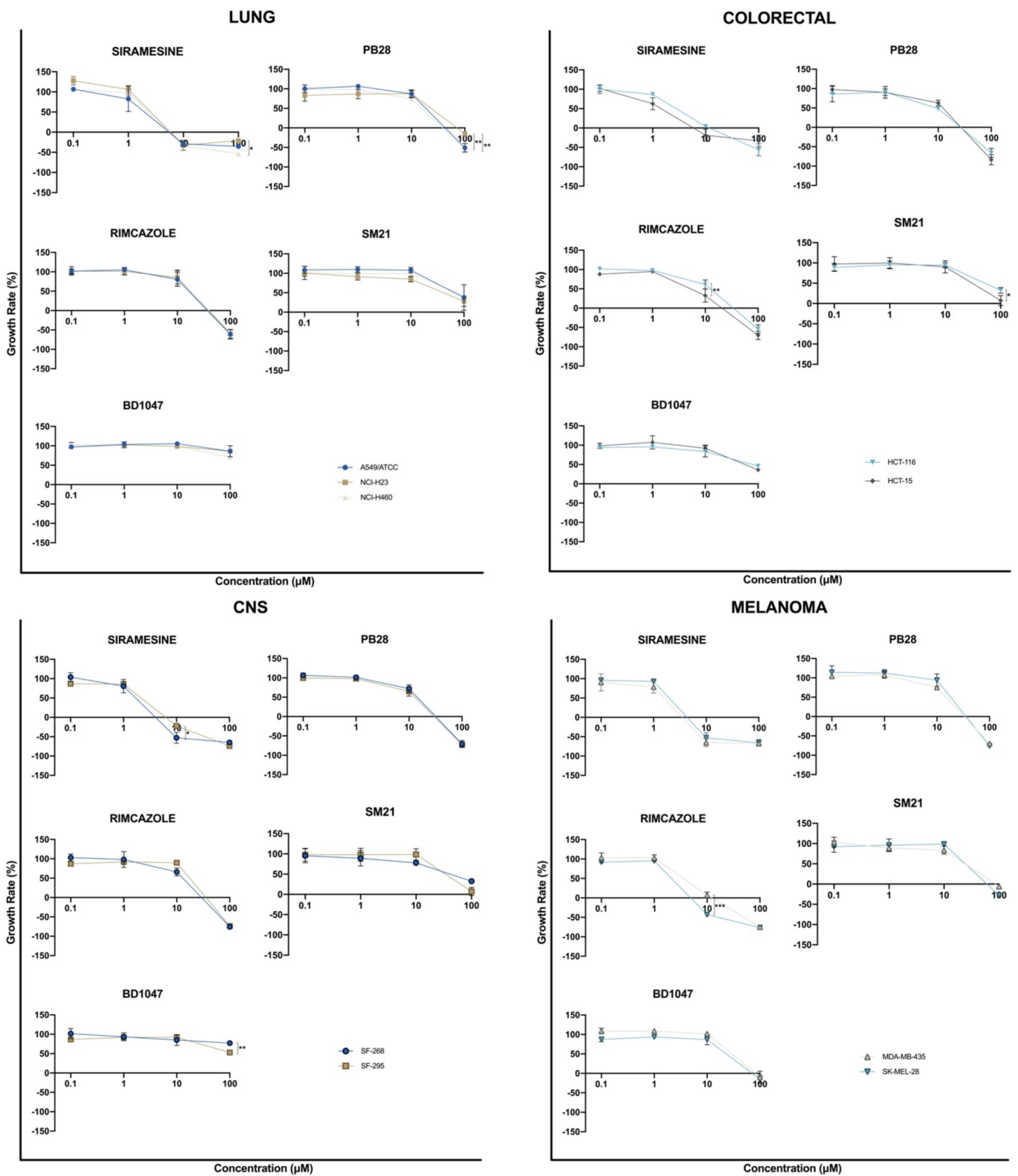

Figure 3. Cont. 

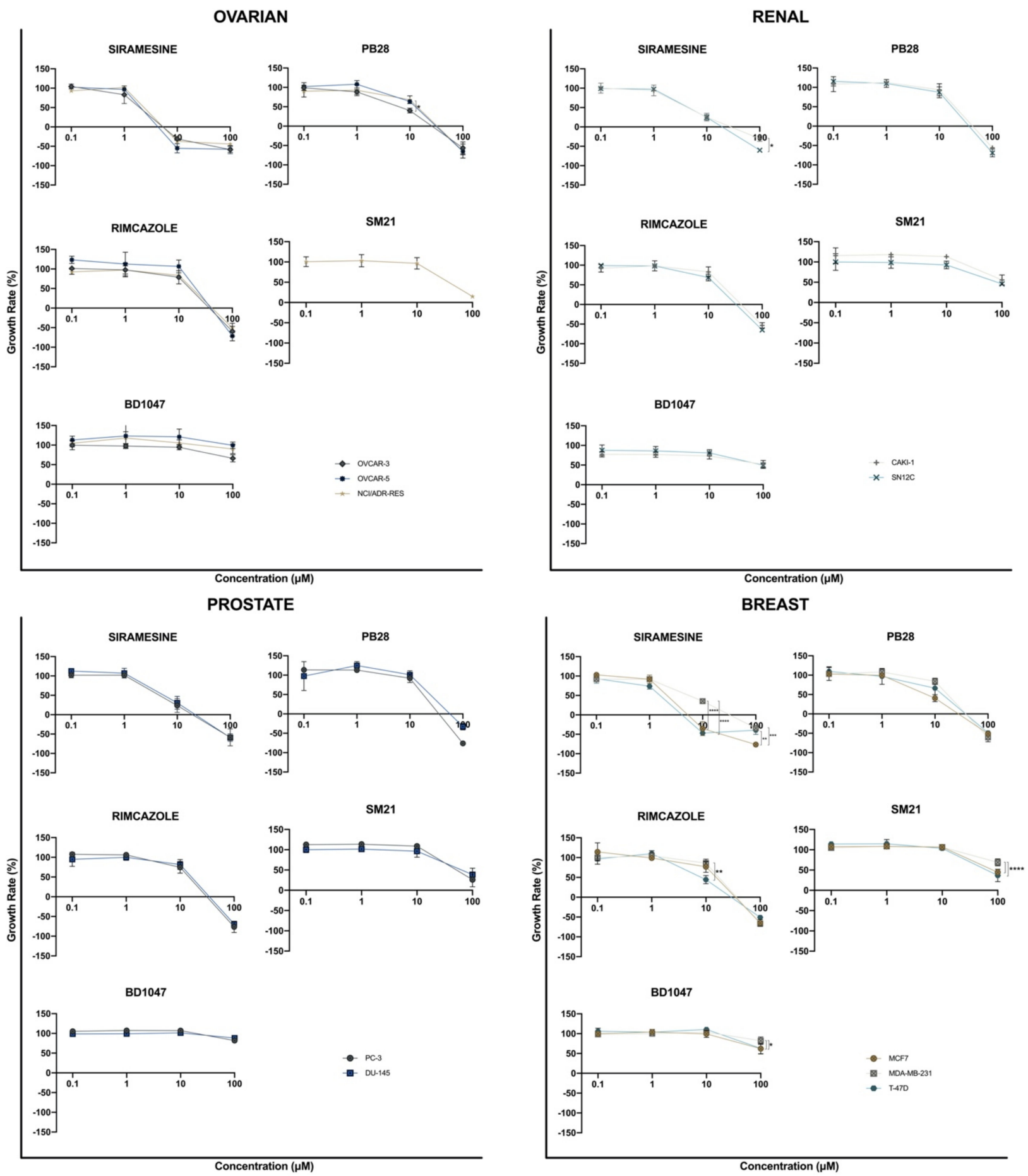

Figure 3. Cont. 


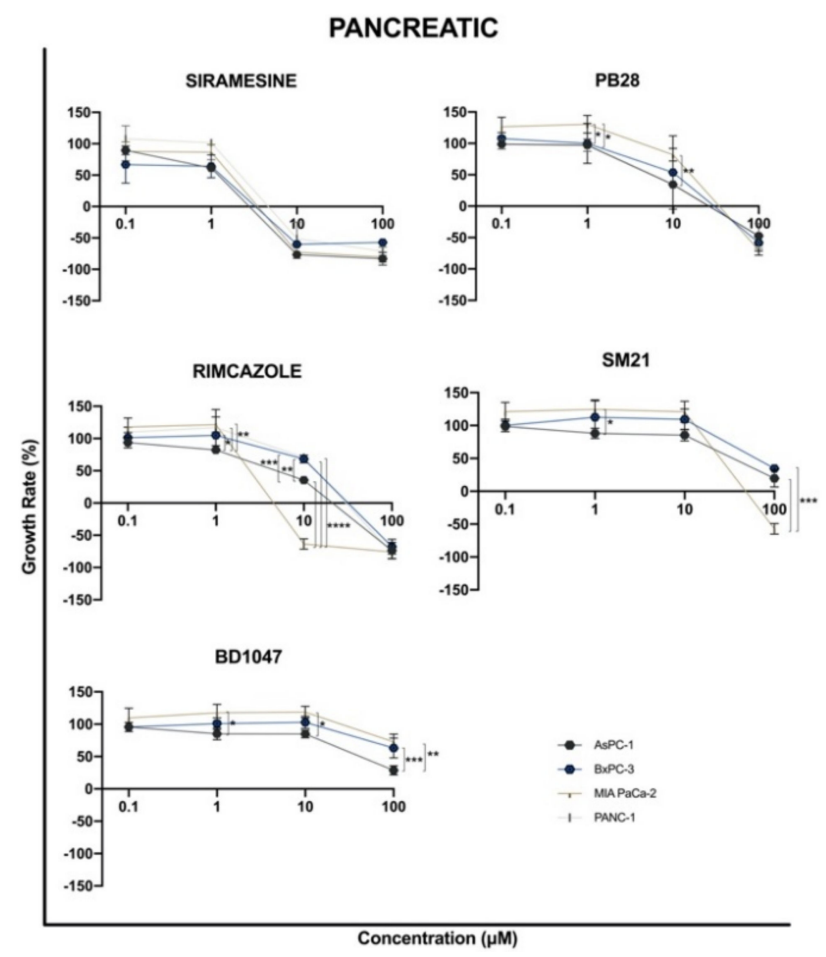

Figure 3. Dose-response effect of the selected sigma ligands siramesine, PB28 dihydrochloride (PB28), rimcazole, SM21 maleate (SM21) and BD1047 dihydrobromide (BD1047) in 23 human cancer cell lines. Cells were exposed to different concentrations of the compounds for $48 \mathrm{~h}$ and growth rates were calculated with sulforhodamine B (SRB) assay. All compounds were tested at four concentrations (one $\log$ serial dilutions from $10^{-4} \mathrm{M}$ to $10^{-7} \mathrm{M}$ ). The results are the average of three independent experiments; each one ran in triplicate. ${ }^{*} p \leq 0.05 ;{ }^{* *} p \leq 0.01 ;{ }^{* * *} p \leq 0.001 ;{ }^{* * * *} p \leq 0.0001$.

From the dose-response curves, $\mathrm{GI}_{50}, \mathrm{TGI}$, and $\mathrm{LC}_{50}$ parameters were calculated for each cell line, representing the antiproliferative, cytostatic, and cytotoxic effects, respectively. Therapeutic index (TI) was also calculated as $\mathrm{LC}_{50}$ to $\mathrm{GI}_{50}$ ratio, determining the relative safety of the compounds (Table 1). 


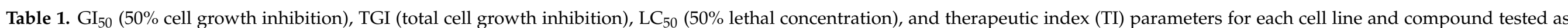

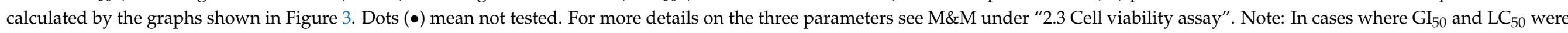
higher than the highest tested concentration $(100 \mu \mathrm{M})$, the TI was calculated using $\mathrm{GI}_{50}$ and $\mathrm{LC}_{50}$ at $100 \mu \mathrm{M}$.

\begin{tabular}{|c|c|c|c|c|c|c|c|c|c|c|c|c|c|c|c|c|c|c|c|c|c|}
\hline \multirow{2}{*}{$\begin{array}{c}\text { CANCER } \\
\text { TYPE }\end{array}$} & \multirow{2}{*}{ CELL LINES } & \multicolumn{4}{|c|}{ SIRAMESINE } & \multicolumn{4}{|c|}{ PB28 } & \multicolumn{4}{|c|}{ RIMCAZOLE } & \multicolumn{4}{|c|}{ SM21 } & \multicolumn{4}{|c|}{ BD1047 } \\
\hline & & GI50 & TGI & LC50 & TI & GI50 & TGI & LC50 & TI & GI50 & TGI & LC50 & TI & GI50 & TGI & LC50 & TI & GI50 & TGI & LC50 & TI \\
\hline \multirow{3}{*}{ NSCL } & A549/ATCC & 3.6 & 7.7 & 11.7 & 3.3 & 34.2 & 66.8 & 99.3 & 2.9 & 29.2 & 61.0 & 92.7 & 3.2 & 84.2 & 100.0 & 100.0 & 1.2 & $>100$ & $>100$ & $>100$ & 1.0 \\
\hline & NCI-H23 & 4.7 & 7.9 & 11.2 & 2.4 & 42.9 & 87.0 & $>100$ & 2.3 & 31.9 & 62.8 & 93.7 & 2.9 & 65.2 & 100.0 & 100.0 & 1.5 & $>100$ & $>100$ & $>100$ & 1.0 \\
\hline & NCI-H460 & 4.3 & 7.7 & 83.1 & 19.3 & 27.5 & 62.6 & 97.7 & 3.6 & 31.6 & 63.6 & 95.6 & 3.0 & 88.9 & 100.0 & 100.0 & 1.1 & $>100$ & $>100$ & $>100$ & 1.0 \\
\hline \multirow{2}{*}{ Colon } & HCT-116 & 5.0 & 15.9 & 90.5 & 18.1 & 9.6 & 48.0 & 87.4 & 9.1 & 18.5 & 57.5 & 96.5 & 5.2 & 74.5 & 100.0 & 100.0 & 1.3 & 89.9 & $>100$ & $>100$ & 1.1 \\
\hline & HCT-15 & 2.4 & 7.9 & 13.5 & 5.6 & 17.9 & 48.6 & 79.4 & 4.4 & 7.5 & 38.5 & 82.1 & 10.9 & 53.7 & 100.0 & 100.0 & 1.9 & 77.8 & $>100$ & $>100$ & 1.3 \\
\hline CNS & SF-268 & 3.1 & 6.4 & 9.8 & 3.2 & 24.0 & 55.5 & 86.9 & 3.6 & 20.1 & 51.9 & 83.7 & 4.2 & 65.5 & 100.0 & 100.0 & 1.5 & $>100$ & $>100$ & $>100$ & 1.0 \\
\hline \multirow{2}{*}{ Melanoma } & MDA-MB-435 & 2.8 & 5.9 & 9.0 & 3.2 & 25.6 & 56.6 & 87.7 & 3.4 & 6.0 & 10.7 & 72.5 & 12.1 & 44.0 & 94.2 & 100.0 & 2.3 & 51.7 & 10.1 & $>100$ & 1.9 \\
\hline & SK-MEL-28 & 3.6 & 6.7 & 0.8 & 2.7 & 33.4 & 59.9 & 86.3 & 2.6 & 3.9 & 7.2 & 28.4 & 7.2 & 44.6 & 80.1 & 100.0 & 2.2 & 42.6 & 86.8 & $>100$ & 2.3 \\
\hline \multirow{3}{*}{ Ovarian } & OVCAR-3 & 3.6 & 7.6 & 71.9 & 20.0 & 8.2 & 47.5 & 94.0 & 11.5 & 28.8 & 61.3 & 93.8 & 3.3 & $\bullet$ & $\bullet$ & $\bullet$ & $\bullet$ & $>100$ & $>100$ & $>100$ & 1.0 \\
\hline & OVCAR-5 & 3.8 & 6.7 & 9.7 & 2.6 & 19.5 & 54.4 & 89.3 & 4.6 & 38.7 & 64.0 & 89.2 & 2.3 & $\bullet$ & $\bullet$ & $\bullet$ & $\bullet$ & $>100$ & $>100$ & $>100$ & 1.0 \\
\hline & $\begin{array}{c}\text { NCI/ADR- } \\
\text { RES }\end{array}$ & 4.3 & 7.6 & $>100$ & 23.3 & 22.3 & 56.3 & 90.2 & 4.0 & 32.4 & 65.9 & 99.3 & 3.1 & 86.3 & 100.0 & 100.0 & 1.2 & $>100$ & $>100$ & $>100$ & 1.0 \\
\hline Kidney & CAKI-1 & 6.8 & 50.7 & $>100$ & 14.7 & 36.4 & 66.5 & 96.5 & 2.7 & 31.8 & 64.8 & 97.8 & 3.1 & 100.0 & 100.0 & 100.0 & 1.0 & $>100$ & $>100$ & $>100$ & 1.0 \\
\hline \multirow{2}{*}{ Prostate } & PC-3 & 7.0 & 35.9 & 90.5 & 12.9 & 32.5 & 59.3 & 86.0 & 2.6 & 24.6 & 31.2 & 84.3 & 3.4 & 73.9 & 100.0 & 100.0 & 1.4 & $>100$ & $>100$ & $>100$ & 1.0 \\
\hline & DU-145 & 7.7 & 40.6 & 90.8 & 11.8 & 44.3 & 77.9 & $>100$ & 2.3 & 28.8 & 58.7 & 88.5 & 3.1 & 82.3 & 100.0 & 100.0 & 1.2 & $>100$ & $>100$ & $>100$ & 1.0 \\
\hline \multirow{3}{*}{ Breast } & MCF7 & 4.0 & 7.5 & 42.3 & 10.7 & 8.6 & 49.8 & 98.8 & 11.5 & 27.1 & 58.8 & 90.5 & 3.3 & 91.8 & 100.0 & 100.0 & 1.1 & $>100$ & $>100$ & $>100$ & 1.0 \\
\hline & MDA-MB-231 & 7.7 & 55.9 & $>100$ & 13.0 & 31.3 & 62.3 & 93.4 & 3.0 & 31.2 & 60.8 & 90.4 & 2.9 & 100.0 & 100.0 & 100.0 & 1.0 & $>100$ & $>100$ & $>100$ & 1.0 \\
\hline & T-47D & 2.8 & 6.5 & 10.2 & 3.6 & 22.8 & 61.8 & $>100$ & 4.4 & 9.2 & 51.9 & 99.1 & 10.8 & 81.8 & 100.0 & 100.0 & 1.2 & $>100$ & $>100$ & $>100$ & 1.0 \\
\hline \multirow{4}{*}{ Pancreas } & AsPC-1 & 1.7 & 5.0 & 8.3 & 4.9 & 7.8 & 47.6 & $>100$ & 13.1 & 7.2 & 39.2 & 80.4 & 11.2 & 58.6 & 100.0 & 100.0 & 1.7 & 65.7 & $>100$ & $>100$ & 1.5 \\
\hline & BxPC-3 & 2.0 & 5.6 & 9.3 & 4.7 & 12.8 & 53.1 & 93.4 & 7.3 & 22.1 & 55.2 & 88.3 & 4.0 & 81.5 & 100.0 & 100.0 & 1.2 & $>100$ & $>100$ & $>100$ & 1.0 \\
\hline & MIAPaCa-2 & 3.1 & 5.9 & 8.7 & 2.8 & 28.8 & 58.5 & 88.1 & 3.1 & 4.5 & 6.9 & 9.3 & 2.1 & 45.8 & 71.1 & 96.4 & 2.1 & $>100$ & $>100$ & $>100$ & 1.0 \\
\hline & PANC-1 & 4.0 & 7.0 & 6.3 & 1.6 & $\bullet$ & $\bullet$ & $\bullet$ & $\bullet$ & 22.6 & 52.9 & 83.3 & 3.7 & $\bullet$ & $\bullet$ & $\bullet$ & $\bullet$ & $\bullet$ & $\bullet$ & $\bullet$ & $\bullet$ \\
\hline MEAN & & 4.3 & 15.3 & 45.0 & 9.2 & 24.6 & 58.8 & 92.4 & 5.0 & 22.3 & 49.6 & 83.3 & 4.9 & 73.6 & 97.3 & 99.8 & 1.4 & 92.1 & 361.1 & 100.0 & 1.1 \\
\hline
\end{tabular}


Siramesine was found to exhibit the best in vitro antiproliferative activity among the sigma ligands tested, as indicated by the low $\mathrm{GI}_{50}$ values in all studied cell lines $\left(\right.$ mean $\left.\mathrm{GI}_{50}=4.3 \mu \mathrm{M}\right)$. Rimcazole $\left(\right.$ mean $\left.\mathrm{GI}_{50}=22.3 \mu \mathrm{M}\right)$ and PB28 $\left(\right.$ mean $\left.\mathrm{GI}_{50}=24.6 \mu \mathrm{M}\right)$ demonstrated moderate antiproliferative efficacy, while SM21 (mean $\mathrm{GI}_{50}=73.6 \mu \mathrm{M}$ ) and BD1047 (mean $\mathrm{GI}_{50}=92.1 \mu \mathrm{M}$ ) showed no significant cell growth inhibition efficacy. Siramesine exhibited the best cytostatic and cytotoxic efficacy, as indicated by the low TGI mean parameter of $15.3 \mu \mathrm{M}$ and low $\mathrm{LC}_{50}$ mean parameter of $45 \mu \mathrm{M}$.

$\mathrm{GI}_{50}, \mathrm{TGI}$, and $\mathrm{LC}_{50}$ parameters of the selected sigma ligands against the 23 established human cancer cell lines were further visualized by heat correlation maps (Figure 4). The parameter values were coded on a warm-to-cool color spectrum in which the warmer color (red) corresponds to the lowest values, while the colder color (light green) corresponds to the highest values. Low parameter values indicate better sigma ligands activity. Figure 4 shows that the $\mathrm{GI}_{50}$ parameter values for siramesine were in the warm range of the color scale (red, light red) in all the tested cancer cell lines, which contrasted with $\mathrm{GI}_{50}$ parameter values for the other tested sigma ligands, which were in the cold color region (green, light green). The same pattern was observed for TGI and $\mathrm{LC}_{50}$ parameters, as siramesine was in the warm region of the color scale in several cell lines, in contrast to the rest of the sigma ligands tested. This indicates that among the sigma ligands studied, the $\sigma 2$ agonist siramesine exhibited the best antiproliferative, cytostatic, and cytotoxic activity. Unlike siramesine, PB28 was found to exhibit significant antiproliferative activity against only four cell lines (HCT116 - colorectal cancer, OVCAR3-ovarian cancer, MCF7—breast cancer, and AsPC1-pancreatic cancer). Interestingly, rimcazole's highest activity was observed against the two melanoma cell lines tested and two out of the four pancreatic cancer cell lines (AsPC1 and MiaPaCa2) tested.

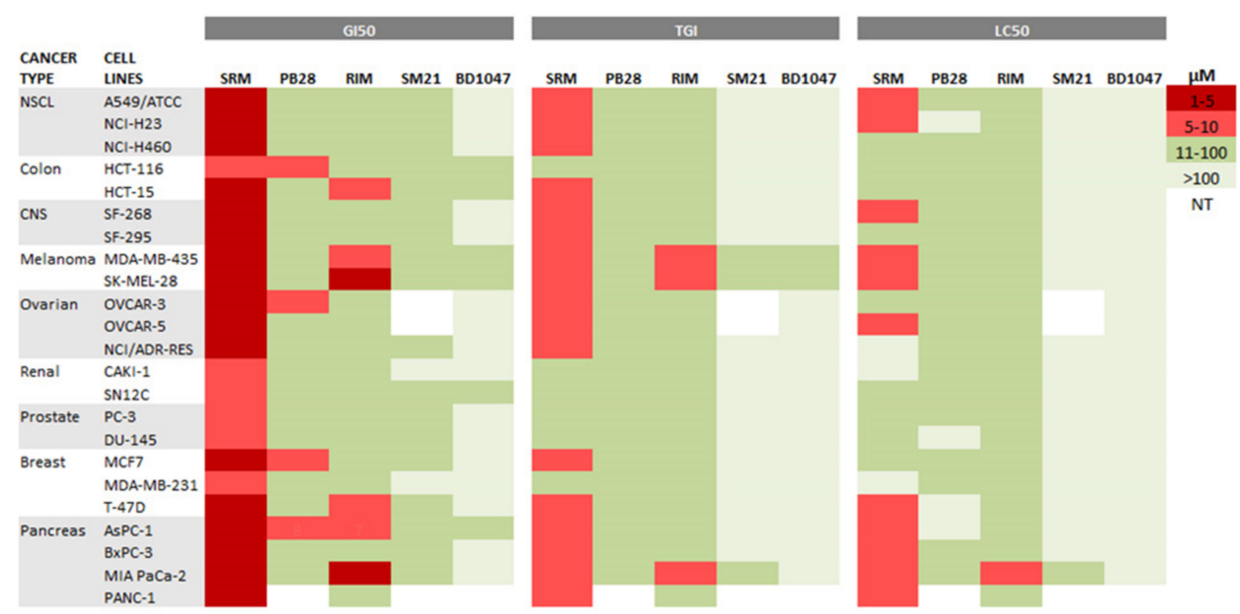

Figure 4. Heat maps representing $\mathrm{GI}_{50}, \mathrm{TGI}$, and $\mathrm{LC}_{50}$ parameters of the sigma ligands tested against 23 human cancer cell lines. A warm-to-cool color spectrum (red $>$ light red $>$ green $>$ light green) is used to represent the parameter value range $(1-5 \mu \mathrm{M}, 5-10 \mu \mathrm{M}, 10-100 \mu \mathrm{M},>100 \mu \mathrm{M})$, respectively. White color stands for not tested (NT) cell lines. SRM: siramesine; RIM: rimcazole.

The therapeutic index (TI) of the selected ligands was also calculated as an $\mathrm{LC}_{50}$ to $\mathrm{GI}_{50}$ ratio as an indicator of the relative safety of a substance (Figure 5). High TI values indicate a more favorable safety profile. Figure 5 shows that the $\sigma 2$ agonist siramesine has a very good therapeutic index $(>10)$ in many of the cell lines studied in comparison to the other sigma ligands tested. 


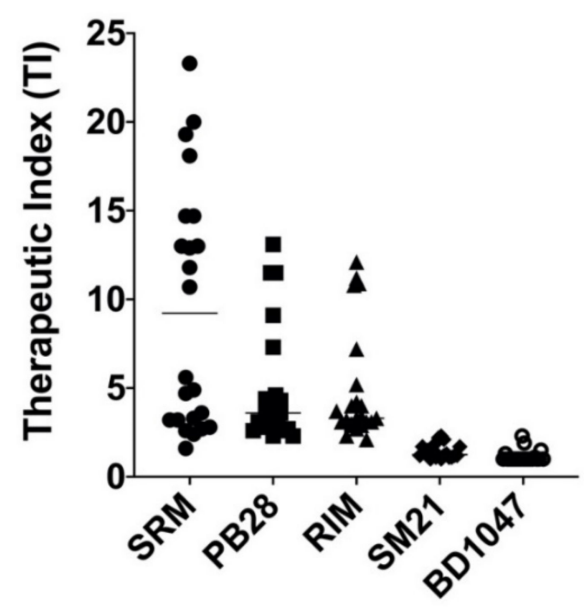

Figure 5. Therapeutic index (TI) values of the selected sigma ligands (SRM, PB28, RIM, SM21, and BD1047) for the 23 human cancer cell lines tested in this study. SRM: siramesine; RIM: rimcazole. Note: In cases where $\mathrm{GI}_{50}$ and $\mathrm{LC}_{50}$ were higher than the highest tested concentration $(100 \mu \mathrm{M})$, the TI was calculated using $\mathrm{GI}_{50}$ and $\mathrm{LC}_{50}$ at $100 \mu \mathrm{M}$.

\subsection{Sigma Ligands' Sensitivity Was Not Correlated to Their Activity as Either Agonists or Antagonists}

We next sought to identify possible patterns in the sigma ligands' sensitivity profiles that could be related to the sigma ligands activity as either agonists or antagonists. $\mathrm{GI}_{50}$ values were normalized using the $\mathrm{z}$-score statistical parameter and grouped by cancer type (Figure 6). The z-score normalization reflects the $\mathrm{GI}_{50}$ deviation from the mean, in terms of standard deviation. Positive and negative values were plotted along a vertical line that represents the mean $\mathrm{GI}_{50}$ value of all the cell lines against the tested sigma ligand. Negative values, projected to the right, represent cellular sensitivities that exceed the mean (i.e., more sensitive cell lines), while positive values, projected to the left, represent cell lines less sensitive to the mean (i.e., more resistant cell lines). Figure 6 shows that there was no distinct sensitivity pattern of the sigma ligands studied herein, regardless of their receptor specificity or the agonistic/antagonistic classification. Instead, it seemed that there was a general sensitivity/resistance pattern, discrete for each cell line, against the effect of the selected sigma ligands. These distinct responses may reflect a cell line or, in some cases, tissue-dependent sigma ligand effect. Indeed, our data suggest that all the lung, renal, and prostate cancer cell lines tested are resistant against all the studied sigma ligands, whereas all colorectal, melanoma, and pancreatic cancer cell lines appeared to be sensitive against the effect of all sigma ligands studied. Focusing on siramesine, which our data indicates has the best in vitro anticancer efficacy, it appears that pancreatic cancer cell lines are more sensitive against siramesine's activity, suggesting that siramesine should be further investigated as a novel putative therapeutic approach in the treatment of pancreatic cancer. 


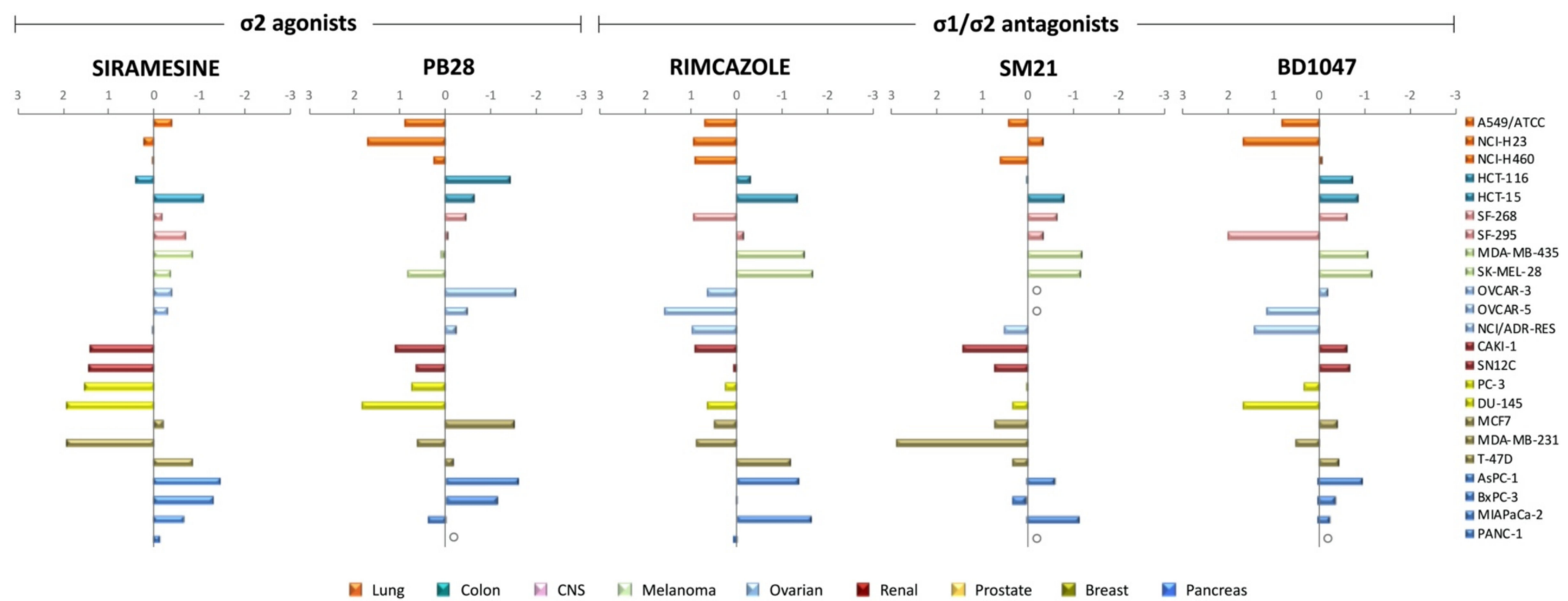

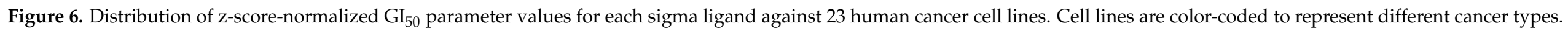

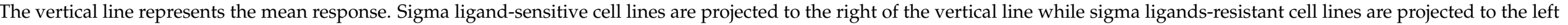
of the vertical line. Open circle $(\bigcirc)$ means not tested. 
3.4. Sigma Receptors Expression Levels Did Not Appear to Correlate with the Sigma Ligands' Antiproliferative Effect

Pearson's linear correlation coefficient $(r)$ was calculated to investigate the relationship between the antiproliferative efficacy of the selected sigma ligands to the expression levels of sigma receptors. The Pearson's $r$ is a statistical measure of the strength of the linear relationship between two variables and is constrained between values $-1 \leq \mathrm{r} \leq 1$. Positive $r$ values denote positive linear correlation while negative values denote negative linear correlation. An $r$ of -1 indicates a perfect negative linear relationship, an $r$ of 0 indicates no linear relationship, and an $r$ of 1 indicates a perfect positive linear relationship. Scatter plots of the tested sigma ligands' antiproliferative effect $\left(\mathrm{GI}_{50}\right)$ versus $\sigma 1$ expression levels (Figure 7a), PGRMC1 expression levels (Figure 7b), and o2/TMEM97 expression levels (Figure 7c) were generated, and the Pearson's $r$ was calculated for each relationship. Figure 7 a shows that there was a weak negative linear correlation $(r=-0.24)$ between siramesine antiproliferative effect and $\sigma 1$ expression levels, while no other significant correlation was reported between the other tested sigma ligand efficacies and the $\sigma 1$ expression levels. Figure $7 \mathrm{~b}$ shows that there was a weak negative linear correlation between siramesine and PB28 antiproliferative effect and PGRMC1 expression levels $(r=-0.2$ and $r=-0.3$, respectively), while no other significant correlation was reported between the other tested sigma ligand efficacies and the PGRMC1 expression levels. Figure 7c shows that there was a weak negative linear correlation between PB28 antiproliferative effect and $\sigma 2 /$ TMEM97 expression levels $(r=-0.22)$, while no other significant correlation was reported between the other tested sigma ligand efficacies and the $\sigma 2 /$ TMEM97 expression levels.

\subsection{Putative Sigma Ligands' Mechanism of Action: Prediction Using the COMPARE Algorithm}

Sigma ligands' possible mechanism of action (MoA) was investigated using the COMPARE algorithm. The COMPARE algorithm from the Developmental Therapeutics Program, $\mathrm{NCI}$, was used at the $\mathrm{GI}_{50}$ level in order to identify compounds from the standard agent database sharing similar mechanisms of growth inhibition with the sigma ligands studied herein. Pairwise correlation coefficients of greater than 0.6 were used as the cut-off for assessing whether two agents were likely to share a similar MoA $[17,18]$. The NCI anticancer screen employs 60 human tumor cell lines (NCI60 panel) that have been grouped in cancer type subpanels. Since pancreatic cancer is not included in the NCI60 panel, COMPARE analysis was performed on 19 of the 23 human cancer cell lines included in this study. Dose-response curves for each cell line assessed against the tested sigma ligands were converted into "endpoint" patterns, thus giving a snapshot of sigma ligands' activity. GI $_{50}$ values for each of the 19 cell lines plotted against the tested sigma ligands were calculated from the dose-response curves (Figure 3) and converted to their $\log 10 \mathrm{GI}_{50}$ values. $\log 10$ $\mathrm{GI}_{50}$ values were averaged, and each value was subtracted from the average to create positive and negative values, referred to as deltas. Plotted delta values along a vertical line represent the mean response of each cell lines in the panel to the test agent. The "mean graph" pattern was unique for each sigma ligand (Figure 8). Positive values project to the right of the vertical line and represent cellular sensitivities to the tested sigma ligand that exceed the mean, while negative values project to the left of the vertical line and represent cell line sensitivities to the tested sigma ligand that were less than the average value. Consistent with our previous observations on the z-score-normalized $\mathrm{GI}_{50}$ parameter values for each cell line (Figure 6), the mean graph display showed little similarities between the sigma ligands tested. 

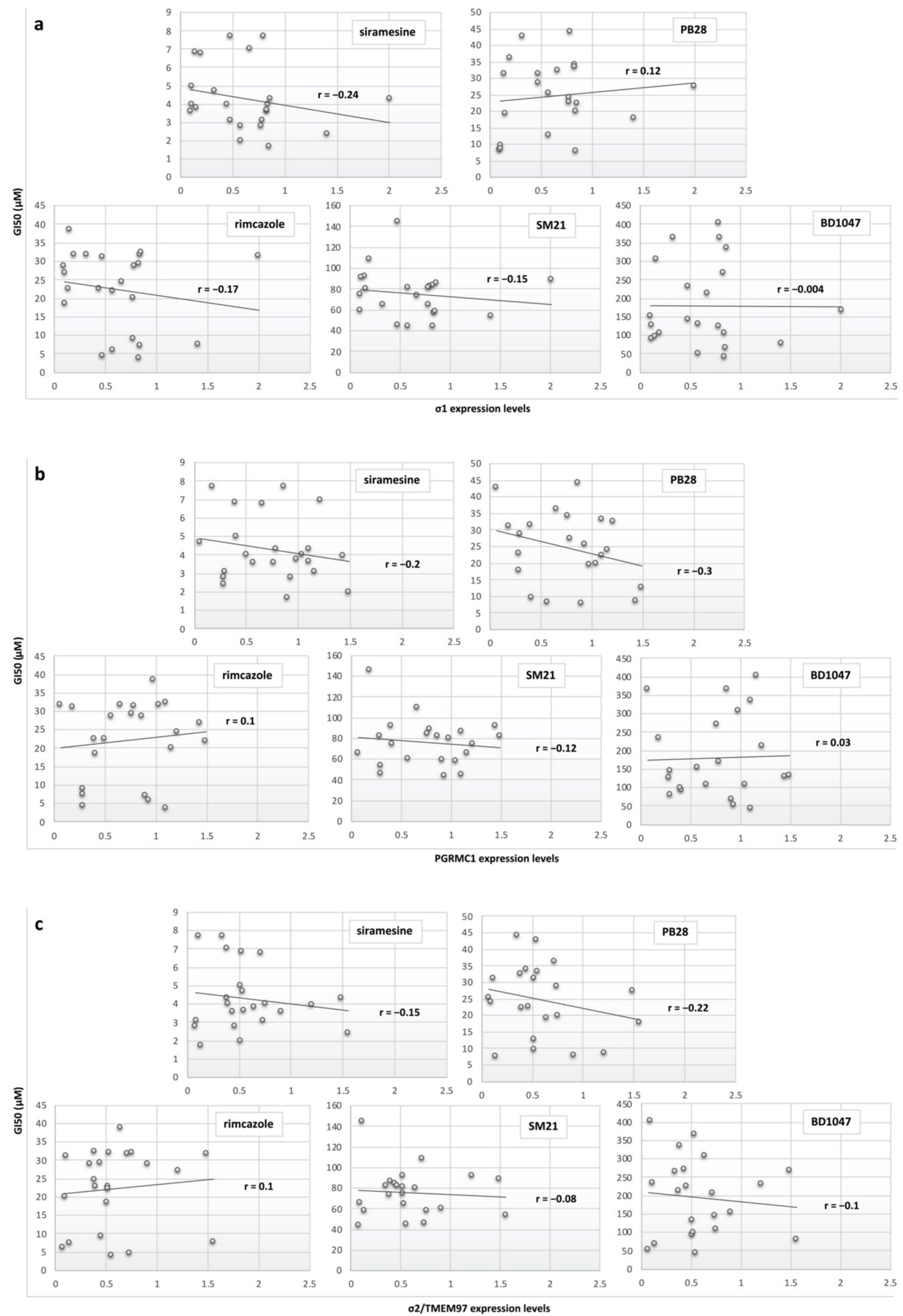

Figure 7. Scatter plots correlating sigma ligand antiproliferative efficacy $\left(\mathrm{GI}_{50}\right)$ versus $\sigma 1$ expression levels (a), PGRMC1 expression levels (b), and o2/TMEM97 expression levels (c). 
SRM

PB28

RIM

SM21

BD1047

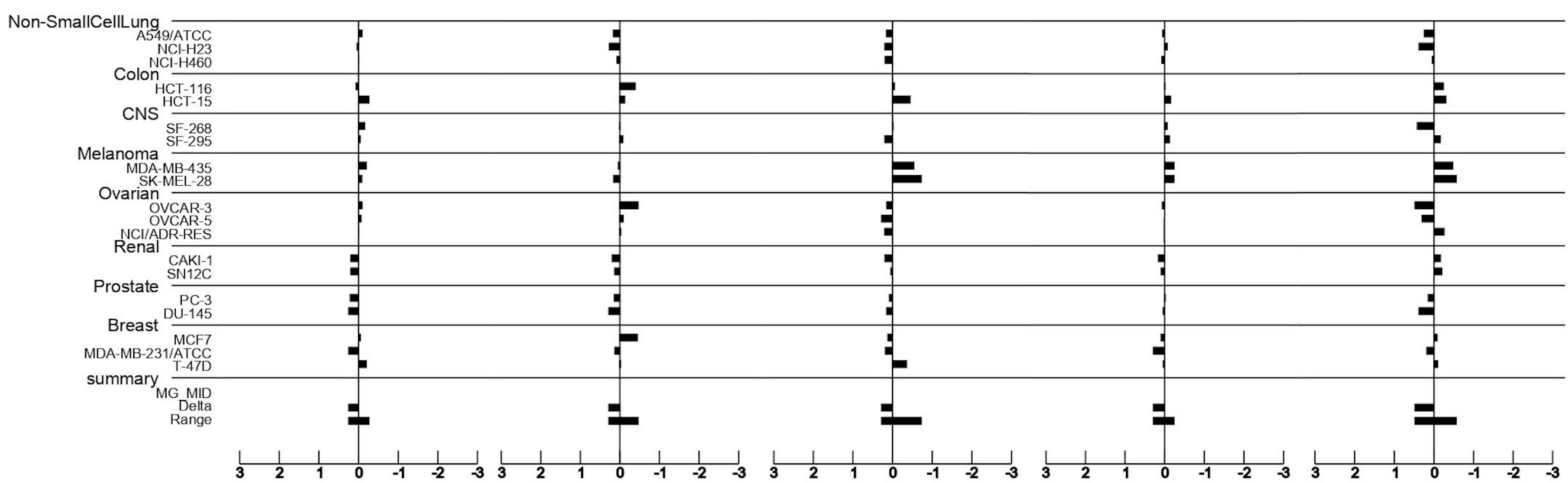

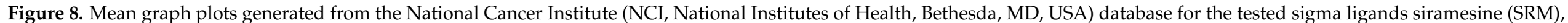

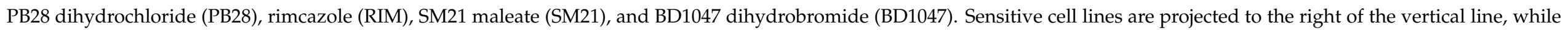

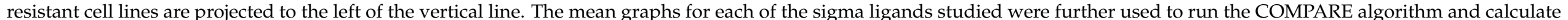

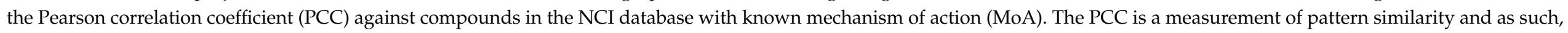

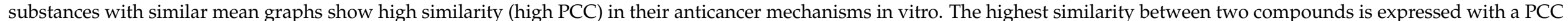

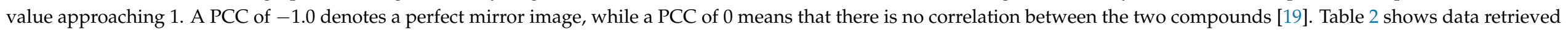

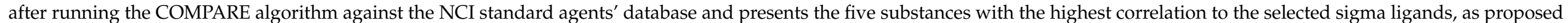
by the algorithm. 
The highest PCC (0.884) was reported for rimcazole to thalicarpine. Thalicarpine (or thaliblastine) is a natural vinca alkaloid with antineoplastic activity, which induces single strand breaks in DNA and arrests cancer cells at the G2/M and G1 phase of the cell cycle. It is also reported to exhibit RNA- and protein synthesis-inhibiting activities [20]. Interestingly, spirogermanium, the second most related compound to rimcazole (PCC 0.687), is also related to protein synthesis inhibition (Table 2, [4]). The second highest correlation, as determined by the PCC, was PB28 with pibenzimol hydrochloride (PCC 0.724), an agent known to inhibit DNA replication by inhibiting topoisomerase I and DNA polymerase. BD1047 and siramesine showed only weak correlations with the tested agents from the standard agents' database (Table 2). BD1047 showed a weak correlation (PCC 0.618) with spirogermanium, which, as mentioned above, is a protein synthesis inhibitor and tamoxifen that reduces DNA synthesis and cellular response to estrogen [21]. Finally, siramesine was found to be weakly associated with dihydro-5-azacytidine (PCC 0.601). Dihydro-5-azacytidine is a synthetic nucleoside analogue of deoxycytidine that inhibits DNA methyltransferase, thereby interfering with abnormal DNA methylation patterns that are associated with genetic instability in some tumor cells consequently acting as an epigenetic modifier drug.

Table 2. The five substances with the highest correlation (PCC) to the selected sigma ligands as proposed by the COMPARE algorithm and their mechanism of action.

\begin{tabular}{|c|c|c|c|}
\hline Ligand & PCC & Target Vector & Mechanism of Action (MoA) \\
\hline \multirow{5}{*}{ Siramesine } & 0.601 & dihydro-5-azacytidine & DNA damage [21] \\
\hline & 0.519 & cyanomorpholino-ADR & Alkylating agent $[22]$ \\
\hline & 0.507 & cytembena & Inhibition of DNA and protein synthesis [23] \\
\hline & 0.487 & anguidine & Inhibition of protein synthesis [21] \\
\hline & 0.462 & caracemide & Inhibition of DNA synthesis [23] \\
\hline \multirow{5}{*}{ PB28 dihydrochloride } & 0.724 & pibenzimol hydrochloride & Inhibition of DNA replication [21] \\
\hline & 0.561 & cytembena & Inhibition of DNA and protein synthesis [23] \\
\hline & 0.514 & chloroquinoxaline sulfonamide & DNA damage [21] \\
\hline & 0.501 & tamoxifen & Inhibition of DNA synthesis [23] \\
\hline & 0.46 & 6-mercaptopurine & Inhibition of DNA synthesis [23] \\
\hline \multirow{5}{*}{$\begin{array}{l}\text { Rimcazole } \\
\text { dihychloride }\end{array}$} & 0.884 & thalicarpine & Inhibition of DNA, RNA, and protein synthesis [24] \\
\hline & 0.687 & spirogermanium & Inhibition of protein synthesis [25] \\
\hline & 0.541 & caracemide & Inhibition of DNA synthesis [21] \\
\hline & 0.516 & tetrocarcin A sodium salt & Inhibition of mitochondrial function [26] \\
\hline & 0.513 & semustine (methyl-CCNU) & Alkylating agent [21] \\
\hline \multirow{5}{*}{ SM21 maleate } & 0.585 & anguidine & Inhibition of protein synthesis [21] \\
\hline & 0.523 & caracemide & Inhibition of DNA synthesis [21] \\
\hline & 0.490 & rhizoxin & Antimitotic agent [21] \\
\hline & 0.485 & tetrocarcin A sodium salt & Inhibit mitochondrial function [26] \\
\hline & 0.466 & didemnin B & Inhibition of protein synthesis [21] \\
\hline \multirow{5}{*}{$\begin{array}{l}\text { BD1047 } \\
\text { dihydrobromide }\end{array}$} & 0.618 & spirogermanium & Inhibition of DNA, RNA, and protein synthesis [25] \\
\hline & 0.618 & tamoxifen & Inhibition of DNA synthesis [21] \\
\hline & 0.575 & chloroquinoxaline sulfonamide & DNA damage [21] \\
\hline & 0.566 & thalicarpine & Inhibition of DNA, RNA, and protein synthesis [24] \\
\hline & 0.543 & flavoneacetic acid & Change the permeability of the tumor vasculature [21] \\
\hline
\end{tabular}

\section{Discussion}

Sigma receptors have attracted increased research interest over the last few decades, as reflected in the growing number of extensive and complex literature published in this rapidly evolving field. It is now undisputed that $\sigma 1$ receptor is an allosteric modulator of multiple cellular signaling systems that, in the context of cancer, act as a chaperone protein, which is a component of the cancer cell support machinery [27]. Until recently, $\sigma 2$ receptor was considered to be related to the progesterone receptor membrane component 
1 (PGRMC1) [5]. More recently, studies have revealed the molecular identification of $\sigma 2$ receptor as TMEM97 [6], thereby elucidating a longstanding pharmacological mystery and paving the way to applying modern molecular biology tools and techniques to mechanistic studies of this receptor. However, the function of $\sigma 2$ receptor remains a mystery and to make things more complex, recent studies show that PGRMC1 and TMEM97 may cooperate and form a ternary complex of LDLR-PGRMC1-TMEM97 that results in the rapid internalization of LDL by LDLR in HeLa cells [8].

Several studies report overexpression of $\sigma$ receptors in cancer; however, these studies mainly involved the indirect detection of $\sigma$ receptors by radio-binding of their selectively labeled ligands [28-31]. In this study, we determined for the first time the expression levels of $\sigma$ receptors by direct detection of their protein expression via Western blotting, investigating the expression levels of the $\sigma 1, \sigma 2 /$ TMEM97, and PGRMC1 receptors simultaneously in 23 human cancer cell lines, representing nine different types of cancer. Our data suggest that $\sigma 1$, PGRMC1, and $\sigma 2 /$ TMEM97 receptors are expressed in the majority of the 23 cell lines tested, exerting different expression patterns without showing any selectivity to a particular cancer type. However, we should emphasize that both $\sigma 1$ and $\sigma 2 /$ TMEM97 showed the highest expression levels in NCI-H460 (non-small cell lung cancer) and HCT-15 (colorectal cancer) cell lines. Of note, several reports suggest overexpression of TMEM97, otherwise known as MAC30, and a correlation with poor outcome in lung and colorectal cancer [32-34]. Moreover, even though the expression of these receptors was diverse, the breast cancer cell line MCF7 expressed high levels (as compared to the majority of the rest of the cancer cell lines tested herein) of both 02 /TMEM97 and PGRMC1 receptors. These findings are to an extent in agreement with data in the literature reporting high expression levels of $\sigma 1$ receptor in lung cancer [35] and high expression levels of $\sigma 2$ [36] and PGRMC1 [37] in MCF7 breast cancer cell line. Further, in agreement with the work published by Vilner et al. based on radio-ligand assays [36], sigma-1 receptor was found to be expressed at very low levels in the MCF7 cell line. Overall, we here provide novel data regarding expression - especially of PGRMC1 and $\sigma 2 /$ TMEM97, for which very little is known [9] - in different human cancer types and cell lines included in a significant tool for anticancer drug development, the NCI60 cell line panel. Additionally, in light of the putative interaction between these two receptors reported previously [8], it seems that their interrelationship is far more complex as this is judged from the differences in their expression levels in the cell lines tested herein.

On the basis of our data showing that $\sigma 1$, PGRMC1, and $\sigma 2 /$ TMEM97 receptors are highly expressed in many of the cell lines tested, we further explored whether sigma receptors mediate the in vitro anticancer activities of five commonly used sigma ligands. In this context, we investigated the in vitro antiproliferative efficacy of siramesine, PB28 dihydrochloride, rimcazole dihydrochloride, BD1047 dihydrobromide, and SM-21 maleate under the same experimental conditions and against the same panel of the 23 human established cancer cell lines in which the expression levels of $\sigma 1$, PGRMC1, and $\sigma 2 /$ TMEM97 receptors were previously studied. The selected sigma ligands were representative sigma agonists and antagonists with high affinities for $\sigma 1$ and/or $\sigma 2$ receptor. It is worth noting that in the literature, the classification of sigma ligands as agonists or antagonists is based on the recapitulation of the $\sigma 1$ gene overexpression or knockdown phenotypes [38]. First, we attempted to identify possible patterns in the sigma ligands' sensitivity profiles that could be related to the sigma ligands activity as either agonists or antagonists. We must underline that this is the first report where the anticancer activity of those agents is tested under the same experimental conditions and following the guidelines and requirements of the NCI Developmental Therapeutics Program (National Cancer Institute, National Institutes of Health, Bethesda, MD, USA; https: / /dtp.cancer.gov/), the most successful and comprehensive program worldwide established since 1955 and dedicated to the discovery and development of anticancer drugs. Through this program, many important anticancer drugs such as taxanes, vinca alkaloids, and even more advanced anticancer approaches such as sipeulucel-T have entered clinics. Our data suggest that under the experimental 
conditions tested in this study, there was no distinct sensitivity pattern between the sigma receptor agonists compared to the sigma receptor antagonists studied. Pearson's linear correlation coefficient $(r)$ was calculated to further investigate the relationship between the antiproliferative efficacy of the selected sigma ligands and the expression levels of sigma receptors. Our data confirmed that there was no significant relationship between sigma receptor expression levels and the sigma ligands' antiproliferative effect $(-0.3<r$ $<0.22$ ). These results indicate that the compounds tested in this study exert their effect mainly through mechanisms that do not involve the $\sigma$ receptors, even though they show in vitro anticancer activity. A recent study by the group of Mach et al. reported that sigma-2 receptor/TMEM97 and PGRMC1 do not mediate sigma-2 ligand cytotoxicity [39], supporting this assumption. Among the tested $\sigma$ ligands, the $\sigma 2$ agonist siramesine was found to exhibit the best antiproliferative, cytostatic, and cytotoxic activity, and thus appears to be the most promising compound. It is also worth noting that, among the nine cancer types studied, pancreatic cancer appears to be the most sensitive cancer type against siramesine. Moreover, of interest is the finding that whilst rimcazole was, in general, found to exert weak anticancer efficacy, the two melanoma cell lines tested were found to be very sensitive to the activity of this compound, even though the $\sigma 1$ levels in these cell lines were not the highest amongst the 23 cell lines tested herein.

An essential missing element in sigma receptor biology in cancer is a clear definition of the underlying molecular MoA that translates into the cellular response of the sigma receptor ligand effect. In the literature, many potential mechanisms of action have been proposed to mediate sigma ligands' anticancer efficacy, including apoptosis [40,41], autophagy [42], lysosomal destabilization [43], mitochondria destabilization [44], and ferroptosis [45,46]. The diversity in the mechanisms of action show that ligand binding of sigma receptors is a multistep process that may be ligand- or cancer type-dependent, thus underlining the significant need to further validate and expand our knowledge in this field. In this context, we attempted to investigate the potential mechanisms of action of the selected sigma ligands using, for the first time in the field, the COMPARE NCI60 anticancer drug screening algorithm. Consistent with our previous observations, the mean graph displays of the NCI60 cell line screening for the selected sigma ligands, showing only minor similarities between the sigma ligands tested. Interestingly, the most common MoA was found to be related to either the synthesis of DNA or the integrity of DNA followed by protein and RNA synthesis inhibition, as judged by the PCC of the sigma ligands and the standard agents returned after running the COMPARE algorithm. It is also important to note that siramesine, which was found to be the most potent agent, appeared to have the highest degree of association with the DNA damage substance dihydro-5-azacytidine, followed by the alkylating agent cyanomorpholino-ADR, although, in general, these are considered to be moderate-to-low associations on the basis of the corresponding PCC. Thus, an interaction of this compound with DNA might be a part of its MoA.

In conclusion, we show that sigma receptors are indeed expressed in the majority of the 23 human cancer cell lines assessed in this study. We provided evidence that sigma receptor expression does not follow a cancer-type pattern or (with some exceptions) a pairwise expression pattern and that it may not mediate the antiproliferative efficacy of a panel of some very common $\sigma$ ligands studied in this report. Among the ligands tested, the $\sigma 2$ receptor ligand siramesine showed the most promising anticancer activity, especially against pancreatic cancer. These findings also provide a platform that rationally warrants the further evaluation of siramesine as a potential anticancer compound, especially against pancreatic cancer.

Author Contributions: Conceptualization, E.S. and K.D.; methodology, E.S., C.T., and E.K.; software E.S.; validation, E.S., C.T., and E.K.; formal analysis, E.S. and K.D.; writing-original draft preparation E.S., N.S., and K.D.; writing-review and editing, E.S., N.S., and K.D.; supervision, K.D.; project administration, K.D.; funding acquisition, K.D. All authors have read and agreed to the published version of the manuscript. 
Funding: This research has been co-financed by the European Union and Greek national funds through the Operational Program Competitiveness, Entrepreneurship and Innovation, under the call RESEARCH-CREATE-INNOVATE (project code: T1EDK-01612 and T1EDK-01833).

Institutional Review Board Statement: Not applicable.

Informed Consent Statement: Not applicable.

Data Availability Statement: The data presented in this study are available within the article. For any further request contact the corresponding author.

Acknowledgments: The authors would like to thank Susan Evans-Axelsson for her great help in critically reading and editing the manuscript.

Conflicts of Interest: The authors declare no conflict of interest.

\section{References}

1. Martin, W.R.; Eades, C.G.; Thompson, J.A.; Huppler, R.E.; Gilbert, P.E. The effects of morphine- and nalorphine-like drugs in the nondependent and morphine-dependent chronic spinal dog. J. Pharmacol. Exp. Ther. 1976, 197, 517-532. [PubMed]

2. Hanner, M.; Moebius, F.F.; Flandorfer, A.; Knaus, H.G.; Striessnig, J.; Kempner, E.; Glossmann, H. Purification, molecular cloning, and expression of the mammalian sigma1-binding site. Proc. Natl. Acad. Sci. USA 1996, 93, 8072-8077. [CrossRef] [PubMed]

3. Kekuda, R.; Prasad, P.D.; Fei, Y.-J.; Leibach, F.H.; Ganapathy, V. Cloning and Functional Expression of the Human Type 1 Sigma Receptor (hSigmaR1). Biochem. Biophys. Res. Commun. 1996, 229, 553-558. [CrossRef] [PubMed]

4. Hayashi, T.; Su, T.P. Sigma-1 receptor chaperones at the ER-mitochondrion interface regulate $\mathrm{Ca}(2+)$ signaling and cell survival. Cell 2007, 131, 596-610. [CrossRef] [PubMed]

5. Xu, J.; Zeng, C.; Chu, W.; Pan, F.; Rothfuss, J.M.; Zhang, F.; Tu, Z.; Zhou, D.; Zeng, D.; Vangveravong, S.; et al. Identification of the PGRMC1 protein complex as the putative sigma-2 receptor binding site. Nat. Commun. 2011, 2, 380. [CrossRef]

6. Alon, A.; Schmidt, H.R.; Wood, M.D.; Sahn, J.J.; Martin, S.F.; Kruse, A.C. Identification of the gene that codes for the sigma2 receptor. Proc. Natl. Acad. Sci. USA 2017, 114, 7160-7165. [CrossRef]

7. Schmit, K.; Michiels, C. TMEM Proteins in Cancer: A Review. Front. Pharm. 2018, 9, 1345. [CrossRef]

8. Riad, A.; Zeng, C.; Weng, C.-C.; Winters, H.; Xu, K.; Makvandi, M.; Metz, T.; Carlin, S.; Mach, R.H. Sigma-2 Receptor/TMEM97 and PGRMC-1 Increase the Rate of Internalization of LDL by LDL Receptor through the Formation of a Ternary Complex. Sci. Rep. 2018, 8, 16845. [CrossRef]

9. Schmidt, H.R.; Kruse, A.C. The Molecular Function of sigma Receptors: Past, Present, and Future. Trends Pharm. Sci. 2019, 40, 636-654. [CrossRef]

10. Georgiadis, M.O.; Karoutzou, O.; Foscolos, A.S.; Papanastasiou, I. Sigma Receptor (sigmaR) Ligands with Antiproliferative and Anticancer Activity. Molecules 2017, 22, 1408. [CrossRef]

11. Covell, D.G.; Huang, R.; Wallqvist, A. Anticancer medicines in development: Assessment of bioactivity profiles within the National Cancer Institute anticancer screening data. Mol. Cancer Ther. 2007, 6, 2261-2270. [CrossRef]

12. Søby, K.K.; Mikkelsen, J.D.; Meier, E.; Thomsen, C. Lu 28-179 labels a sigma(2)-site in rat and human brain. Neuropharmacology 2002, 43, 95-100. [CrossRef]

13. Berardi, F.; Colabufo, N.A.; Giudice, G.; Perrone, R.; Tortorella, V.; Govoni, S.; Lucchi, L. New sigma and 5-HT1A receptor ligands: Omega-(tetralin-1-yl)-n-alkylamine derivatives. J. Med. Chem. 1996, 39, 176-182. [CrossRef]

14. Ferris, R.M.; Tang, F.L.; Chang, K.J.; Russell, A. Evidence that the potential antipsychotic agent rimcazole (BW 234U) is a specific, competitive antagonist of sigma sites in brain. Life Sci. 1986, 38, 2329-2337. [CrossRef]

15. Ghelardini, C.; Galeotti, N.; Gualtieri, F.; Bellucci, C.; Manetti, D.; Giotti, A.; Malmberg-Aiello, P.; Galli, A.; Bartolini, A. Antinociceptive profile of 3-alpha-tropanyl 2-(4-Cl-phenoxy)butyrate (SM-21) [corrected]: A novel analgesic with a presynaptic cholinergic mechanism of action. J. Pharm. Exp. 1997, 282, 430-439.

16. Matsumoto, R.R.; Bowen, W.D.; Tom, M.A.; Vo, V.N.; Truong, D.D.; De Costa, B.R. Characterization of two novel sigma receptor ligands: Antidystonic effects in rats suggest sigma receptor antagonism. Eur. J. Pharm. 1995, 280, 301-310. [CrossRef]

17. Developmental Therapeutics Program. Available online: https://dtp.cancer.gov/databases_tools/compare.htm (accessed on 24 March 2020).

18. Mahaira, L.G.; Tsimplouli, C.; Sakellaridis, N.; Alevizopoulos, K.; Demetzos, C.; Han, Z.; Pantazis, P.; Dimas, K. The labdane diterpene sclareol (labd-14-ene-8, 13-diol) induces apoptosis in human tumor cell lines and suppression of tumor growth in vivo via a p53-independent mechanism of action. Eur. J. Pharmacol. 2011, 666, 173-182. [CrossRef]

19. Holbeck, S.L.; Collins, J.M.; Doroshow, J.H. Analysis of Food and Drug Administration-approved anticancer agents in the NCI60 panel of human tumor cell lines. Mol. Cancer 2010, 9, 1451-1460. [CrossRef]

20. Allen, L.M.; Creaven, P.J. Inhibition of Macromolecular Biosynthesis in Cultured L1210 Mouse Leukemia Cells by Thalicarpine (NSC 68075). Cancer Res. 1973, 33, 3112-3116.

21. NCI Drug Dictionary. Available online: https://www.cancer.gov/publications/dictionaries/cancer-drug (accessed on 26 December 2020). 
22. Wilson, J.J.; Lippard, S.J. In vitro anticancer activity of cis-diammineplatinum(II) complexes with $\beta$-diketonate leaving group ligands. J. Med. Chem. 2012, 55, 5326-5336. [CrossRef]

23. Jackson, R.C.; Taylor, G.A.; Harrap, K.R. Aspects of the biochemical pharmacology of cytembena. Neoplasma 1975, 22, 259-268.

24. Isah, T. Anticancer Alkaloids from Trees: Development into Drugs. Pharm. Rev. 2016, 10, 90-99. [CrossRef]

25. Slavik, M.; Blanc, O.; Davis, J. Spirogermanium: A new investigational drug of novel structure and lack of bone marrow toxicity. Investig. New Drugs 1983, 1, 225-234. [CrossRef]

26. Fang, J.; Zhang, Y.; Huang, L.; Jia, X.; Zhang, Q.; Zhang, X.; Tang, G.; Liu, W. Cloning and Characterization of the Tetrocarcin A Gene Cluster from Micromonospora chalcea NRRL 11289 Reveals a Highly Conserved Strategy for Tetronate Biosynthesis in Spirotetronate Antibiotics. J. Bacteriol. 2008, 190, 6014-6025. [CrossRef]

27. Mori, T.; Hayashi, T.; Hayashi, E.; Su, T.P. Sigma-1 receptor chaperone at the ER-mitochondrion interface mediates the mitochondrion-ER-nucleus signaling for cellular survival. PLoS ONE 2013, 8, e76941. [CrossRef]

28. Leithner, K.; Wohlkoenig, C.; Stacher, E.; Lindenmann, J.; Hofmann, N.A.; Gallé, B.; Guelly, C.; Quehenberger, F.; Stiegler, P.; Smolle-Jüttner, F.M.; et al. Hypoxia increases membrane metallo-endopeptidase expression in a novel lung cancer ex vivo model—role of tumor stroma cells. BMC Cancer 2014, 14, 40. [CrossRef]

29. Spruce, B.A.; Campbell, L.A.; McTavish, N.; Cooper, M.A.; Appleyard, M.V.; O’Neill, M.; Howie, J.; Samson, J.; Watt, S.; Murray, K.; et al. Small molecule antagonists of the sigma-1 receptor cause selective release of the death program in tumor and self-reliant cells and inhibit tumor growth in vitro and in vivo. Cancer Res. 2004, 64, 4875-4886. [CrossRef]

30. Schrock, J.M.; Spino, C.M.; Longen, C.G.; Stabler, S.M.; Marino, J.C.; Pasternak, G.W.; Kim, F.J. Sequential cytoprotective responses to Sigma1 ligand-induced endoplasmic reticulum stress. Mol. Pharm. 2013, 84, 751-762. [CrossRef]

31. Brune, S.; Schepmann, D.; Lehmkuhl, K.; Frehland, B.; Wünsch, B. Characterization of Ligand Binding to the $\sigma 1$ Receptor in a Human Tumor Cell Line (RPMI 8226) and Establishment of a Competitive Receptor Binding Assay. Assay Drug Dev. Technol. 2011, 10, 365-374. [CrossRef]

32. Han, K.Y.; Gu, X.; Wang, H.R.; Liu, D.; Lv, F.Z.; Li, J.N. Overexpression of MAC30 is associated with poor clinical outcome in human non-small-cell lung cancer. Tumour Biol. 2013, 34, 821-825. [CrossRef]

33. Moparthi, S.B.; Arbman, G.; Wallin, A.; Kayed, H.; Kleeff, J.; Zentgraf, H.; Sun, X.F. Expression of MAC30 protein is related to survival and biological variables in primary and metastatic colorectal cancers. Int. J. Oncol. 2007, 30, 91-95. [CrossRef] [PubMed]

34. Ding, H.; Gui, X.H.; Lin, X.B.; Chen, R.H.; Cai, H.R.; Fen, Y.; Sheng, Y.L. Prognostic Value of MAC30 Expression in Human Pure Squamous Cell Carcinomas of the Lung. Asian Pac. J. Cancer Prev. 2016, 17, 2705-2710. [PubMed]

35. Aydar, E.; Onganer, P.; Perrett, R.; Djamgoz, M.B.; Palmer, C.P. The expression and functional characterization of sigma (sigma) 1 receptors in breast cancer cell lines. Cancer Lett. 2006, 242, 245-257. [CrossRef]

36. Vilner, B.J.; John, C.S.; Bowen, W.D. Sigma-1 and sigma-2 receptors are expressed in a wide variety of human and rodent tumor cell lines. Cancer Res. 1995, 55, 408-413. [PubMed]

37. Neubauer, H.; Adam, G.; Seeger, H.; Mueck, A.O.; Solomayer, E.; Wallwiener, D.; Cahill, M.A.; Fehm, T. Membrane-initiated effects of progesterone on proliferation and activation of VEGF in breast cancer cells. Climacteric 2009, 12, 230-239. [CrossRef] [PubMed]

38. Nguyen, L.; Lucke-Wold, B.P.; Mookerjee, S.A.; Cavendish, J.Z.; Robson, M.J.; Scandinaro, A.L.; Matsumoto, R.R. Role of sigma-1 receptors in neurodegenerative diseases. J. Pharm. Sci. 2015, 127, 17-29. [CrossRef]

39. Zeng, C.; Weng, C.-C.; Schneider, M.E.; Puentes, L.; Riad, A.; Xu, K.; Makvandi, M.; Jin, L.; Hawkins, W.G.; Mach, R.H. TMEM97 and PGRMC1 do not mediate sigma-2 ligand-induced cell death. Cell Death Discov. 2019, 5, 58. [CrossRef]

40. Crawford, K.W.; Bowen, W.D. Sigma-2 receptor agonists activate a novel apoptotic pathway and potentiate antineoplastic drugs in breast tumor cell lines. Cancer Res. 2002, 62, 313-322.

41. Kashiwagi, H.; McDunn, J.E.; Simon, P.O.; Goedegebuure, P.S.; Xu, J.; Jones, L.; Chang, K.; Johnston, F.; Trinkaus, K.; Hotchkiss, R.S.; et al. Selective sigma-2 ligands preferentially bind to pancreatic adenocarcinomas: Applications in diagnostic imaging and therapy. Mol. Cancer 2007, 6, 48. [CrossRef]

42. Zeng, C.; Rothfuss, J.; Zhang, J.; Chu, W.; Vangveravong, S.; Tu, Z.; Pan, F.; Chang, K.C.; Hotchkiss, R.; Mach, R.H. Sigma-2 ligands induce tumour cell death by multiple signalling pathways. Br. J. Cancer 2012, 106, 693-701. [CrossRef]

43. Ostenfeld, M.S.; Fehrenbacher, N.; Høyer-Hansen, M.; Thomsen, C.; Farkas, T.; Jäättelä, M. Effective tumor cell death by sigma-2 receptor ligand siramesine involves lysosomal leakage and oxidative stress. Cancer Res. 2005, 65, 8975-8983. [CrossRef] [PubMed]

44. Hafner Česen, M.; Repnik, U.; Turk, V.; Turk, B. Siramesine triggers cell death through destabilisation of mitochondria, but not lysosomes. Cell Death Dis. 2013, 4, e818. [CrossRef] [PubMed]

45. Ma, S.; Henson, E.S.; Chen, Y.; Gibson, S.B. Ferroptosis is induced following siramesine and lapatinib treatment of breast cancer cells. Cell Death Dis. 2016, 7, e2307. [CrossRef] [PubMed]

46. Bai, T.; Wang, S.; Zhao, Y.; Zhu, R.; Wang, W.; Sun, Y. Haloperidol, a sigma receptor 1 antagonist, promotes ferroptosis in hepatocellular carcinoma cells. Biochem. Biophys. Res. Commun. 2017, 491, 919-925. [CrossRef] 